\title{
Teaching Building Design and Construction Engineering. Are we ready for the paradigm shift?
}

\author{
Daniel, Forgues, Architect, \\ $\mathrm{PhD}$ \\ Professor, Construction \\ Engineering \\ École de Technologie \\ Supérieure \\ daniel.forgues@etsmtl.ca
}

\author{
Sheryl Staub-French, \\ PhD, PEng \\ Associate Professor, \\ Civil Engineering \\ University of British \\ Columbia \\ ssf@civil.ubc.ca
}

\author{
Leila M. Farah, MArch \\ Lecturer, Architecture \\ McGill University \\ leila.farah@mcgill.ca
}

\begin{abstract}
Drastic changes are occurring in the construction industry. Building Information Modeling (BIM) processes and technologies, and new Integrated Project Delivery (IPD) approaches are transforming the way buildings are planned, designed, built and operated. With the needs for new skills to cope with these accelerating changes, architecture, engineering and construction (AEC) associations in the United States are working with universities to reengineer teaching programs, integrating architecture training within an engineering and construction curriculum. Leading universities are already developing new programs, such as BIM studio courses, and promoting new ways to teach practice knowledge within design laboratories.

These changes are also starting to occur in the Canadian industry. Some large governmental bodies are starting to request that their projects are designed and built using BIM. Canadian universities must respond to these changing requirements to prepare future architects, engineers, and construction managers for these new challenges and emerging industry needs. This paper provides examples for how to bridge this gap by bringing practice knowledge and research to the classroom. First, it synthesizes the impact of BIM and IPD on engineering practices in Canada. Second, it describes curriculum development undertaken between a school of architecture and two engineering departments for the development of multidisciplinary design studios to teach integrated design and BIM. Case studies are set in urban contexts and include the development of new buildings as well as refurbishment proposals for an industrial obsolete landmark. Finally, learning from this teaching and research experience, it raises
\end{abstract}

questions and issues regarding our readiness to cope with this paradigm shift.

\section{Introduction}

The introduction of BIM as a new collective design artefact has a tremendous impact on existing design professional practices. Virtual integration using a shared and integrated data model has been widely recognized in research and in industry as a solution to the challenge of fragmentation. For the past century, the design process (its work organization, planning and building design) has barely evolved compared to other industries; and this division of tasks between design specialists in professional practice has likewise been adopted in education. This fragmented and disjointed organization of work is now considered as a root cause of the industry's poor productivity, the lack of predictability in the delivery of the building product, and a significant number of deficiencies.

BIM is a collective object, a virtual model of the building, to be developed and managed jointly by integrated design and construction teams. Moving from specialized design artefacts to this unique and integrated model challenges the core of research, professional practice and education. For example, as asserted by Lawson [1], the perception of design being the result of one individual creative act is rooted in architecture training and deeply embedded in their practice knowledge and tools.

We posit that the successful application of BIM in the construction industry is a paradigm shift, but not in the traditional sense as described by Kuhn [2]. It is not driven by science but by a new model of integrated practices, as embodied in IPD practices. This shift is creating enormous pressure on education to rethink how design and construction are taught to architects, engineers, and construction 
managers, and also how knowledge is generated, mediated and formalized into new ways of organizing work.

BIM is now used by $70 \%$ of the US industry [3]. However, while some universities work closely with the industry to develop new integrated approaches and adjust their curricula accordingly, the core of education and research has difficulty coping with industry needs [3] and is lagging behind, even though this problem was acknowledged by professional associations in 2006 [4].

The problem may not seem as acute in Canada, since Canada is generally lagging behind in BIM adoption, and has yet to follow the aggressive mandates set by the US General Services Association (GSA), which required BIM on all federal building projects since 2007. In Canada, changes are nonetheless happening and according to our research, there is an equally urgent need for Canadian universities to rethink the way they are conducting research and teaching design sciences related to building construction. This paper describes some of the changes that are occurring in North America, the widening gap between research, education and industry needs, and some reflections and lessons learned based on the authors' experience researching and teaching BIM and integrated practice.

\section{Why BIM and IPD are transforming design \& construction practices, research and education}

A paradigm shift occurs when traditional techniques and beliefs are abandoned and replaced by new ones. BIM is a product, enabled by a new set of technologies, which is transforming the way buildings are planned, designed, built and operated. BIM is also a process that is redefining how work is organized, moving away from a division of tasks between specialties to agile workflows and data management. In theory, developing a unique model shared by all the project stakeholders throughout the design process and product lifecycle entails a reorganization of work around this unique collective object. As asserted by Broshar et al. [4]:

"These new representational technologies clear a space for teachers and practitioners to reexamine the underlying principles of professional education... So the question is: How might we reformulate the curriculum in view of emerging technologies that allow owners, architects, contractors, and subcontractors to virtually manipulate construction in real time, with exacting precision, earlier in the process-during schematic design-such that all parties to the contract enjoy equal access to the model; and such that any change in the assembly of the building or its structure or enclosure or mechanical systems registers instantly and uniformly throughout the composition, adjusting for price, size, and performance, among other parameters? In other words, if this technology stimulates the reformation of architectural services around emerging diagrams of integrative practice, what would a correspondingly integrative curriculum look like?”

Architectural and engineering research and education is compartmentalized due to university and faculty structures. The major drawback of the current educational system is the fact that students acquire design competences that may be obsolete in their future practice, and that they are not prepared to work within integrated digital environments.

\section{How can research and education cope with this paradigm shift?}

Researchers and educators in the US have started to explore this limitation. Alternatives to improving existing programs include the introduction of BIM training in existing curricula. This is a challenging task since very few faculty members have the expertise to teach such courses.

But the core problem is the lack of recognition in research and education that existing approaches to improve the curricula will not be sufficient. The industry is rapidly moving from fragmented to integrated practices through IPD. The boundaries between specialties are disappearing, hence, redefining the lines of power and influence within the supply chain. Design no longer belongs to the realm of design professionals; sub-trades are now participating in the design process and share in the ownership of the model.

Theory considers that a paradigm shift is a normal process based on convergent or consensusbound research that ultimately results in revolution. Then new principles and methods are generated, transforming practices [2]. What happens when the shift does not come from science but from practice?

In design science, a core research and education principle is that knowledge is first generated by research, and is then transferred to practice through education. New theories of practices posit that work is organized around 
specialized practices built around objects or artefacts. Design professionals are surrounded by such objects: design, validation and sharing tools. The scientific literature also describes some of these design artefacts as boundary objects: tools and technology that help different practices to build a common representation of a problem and its solution. They are not only perceived as a means to represent and share knowledge (mutual learning) but also as ways to stimulate the coproduction of new knowledge.

However, a paradigm shift requires discarding or changing obsolete practices and related knowledge. Rules and methods related to design are embedded in these objects defining practices. Therefore, introducing complex configurational technologies, like BIM, as a new collective object force design and construction professionals to rethink the way they work, and to help generate new knowledge [5]. The question is: how can research and education in construction position itself within a practice-driven paradigm shift?

Understanding how research can advance scientific and empirical knowledge is an ongoing challenge for scholars researching professional practices [6]. Simon [7] argues that the "raison d'être" for research in design is to advance both science and practices. But this role remains elusive, hence the justification of design science as a new scientific paradigm aimed at creating "practice knowledge." Design practices struggle to adapt to the shift in the paradigm of work from fragmented to integrated design. The knowledge is not available, it has to be created. Van De Ven [6] posits that scholars face a similar problem, not being able to break knowledge barriers between domains of professional expertises, and calls for new approaches to research, devised for the coproduction of knowledge between scholars and practitioners. He identifies design science as a form of engaged scholarship, and describes the engaged scholar as someone who views organisations and communities of practitioners as a learning workplace (idea factory). In such a setting, practitioners and scholars co-produce knowledge on key identified issues, test and develop alternative ways of approaching a common problem.

\section{The need to transform AEC research and education}

We posit that research and education has to accomplish a paradigm shift that mirrors the industry around BIM as a new collective object. The core issues, however, are (1) that research and education are built on a rigid and fragmented structure that often resists change; and (2) as opposed to industry, educational institutions are not pressured by the market to make these changes.

In the US, professional and industry associations reacted to new BIM related procurement rules by working together in redefining and integrating practices. There was already an underlying structure that started to take place after the CICE report in 1986 with the creation of the Construction Industry Institute (CII). CII built this learning space between industry and research, a fertile ground to develop the learning workspace necessary to build practice knowledge around BIM as the collective object. It stimulated exchanges within education and industry about rethinking the curriculum. However, for the reasons mentioned earlier, the changes are far from occurring as fast as in the industry, creating a widening gap between education and practice. There are nonetheless some innovative initiatives emerging in US universities that are suitable to use as models to define ways of addressing these issues.

One of the first educational initiatives focusing on BIM and integrated practice was developed at Stanford University in 1993. They developed a course, Computer Integrated Architecture, Engineering and Construction, that engages universities from US, Japan, and Europe. The course objective is to develop a methodology and environment for team-based approaches to $\mathrm{A} / \mathrm{E} / \mathrm{C}$ design. Architecture, engineering and construction students work in geographically distributed multi-disciplinary teams. Students learn about cross-disciplinary impacts and integration issues, the use of collaboration technologies, team dynamics and collaborative work, and the impact of collaboration technologies on organization performance [8]. A second initiative worth noting was developed at Penn State University (PSU). PSU was mandated by CII to develop a BIM execution plan. This initiative not only stimulated the accelerated training of highly qualified personnel, but also contributed to the development of a set of novel BIM courses. PSU has now integrated BIM into every year of their 5-year program. The students experience culminates with a BIM capstone project and a collaborative BIM studio. The BIM studio in particular is quite unique because it creates multi-disciplinary teams of architects and landscape architects, structural, mechanical, electrical and lighting engineers, and construction managers that 
collaboratively develop a BIM using state-of-the-art collaboration technology.

Finally, the buildingSMART alliance and the BIMForum sponsor an academic workshop at the Ecobuild Conference each year, which offers tracks on BIM, IPD and sustainability. The objective of the conference is to gather representatives of different academic programs and industry to discuss the core educational principles for technology-based collaboration in AEC and Facilities Management, and to identify directives guiding the incorporation of these principles into college curriculum.

The situation is quite different in Canada. Associations representing the industry are much more fragmented than in the US, and public clients are less inclined to impose BIM. Although there are some indications that the industry is changing, as evidenced by the intent of Infrastructure Alberta and PWGSC to require BIM for major projects, similar indicators in education and research do not exist. In fact, the discussion on how we should change our curricula is just barely started. In Canada, the relationship between industry and research is weaker than in the United States, and as a result, the time required to adjust our curricula may take longer. In the Canadian context we must devise a strategy that takes into account the peculiarities of our industry and our educational system. Next, we describe some on-going initiatives that could be used as springboards for a deeper reflection regarding the future of AEC education in Canada.

\section{An approach to cogenerate knowledge of practices}

There are two initiatives described in this paper regarding co-generation of practice knowledge around BIM and IPD: (1) In the first, research students observe how design and construction teams collaborate with BIM technologies with the aim of capturing, enhancing and formalizing this new practice knowledge, (2) In the second, students experiment with integrated design in BIM studios involving different departments.

A key success factor in BIM adoption is for AEC professionals to work collaboratively. The conceptual phase is paramount since $85 \%$ of the decisions are made during this phase. The conceptual phase is a complex process; "for it entails grappling with the articulation of a desired future state under high level of uncertainty" [9]. It is viewed by scholars as a process of solving a wicked problem. This is distinguished from a tame problem in both the challenges it poses and the identification of solutions. A tame problem is amenable to mathematical modeling. Problems are clearly defined and can be solved with a rigorously technical problem-solving approach based on scientific knowledge [9]. As the level of uncertainty decreases and the definition of the project becomes more precise, wicked problems evolve into tame problems. For example, defining the configuration and the shape of a building can be defined as a wicked problem, whereas sizing of a beam to support a given load can be viewed as a tame problem. In the traditional division of work, architects are responsible for the wicked problems and engineers for the tame. Therefore engineers' input in the initial phases of design is challenging.

As opposed to architects who focus on finding holistic solutions to complex problems in the design process, engineers are concerned about specifics on how things "perform" or "behave" within defined systems [10]. Thus, in the quest to develop a shared mental model with the other members of the team, engineers face the main challenges. Psychological ownership relies on the team's ability to agree on a shared set of rules and a process for decision-making. The ownership is fragmented between architects' ideas and engineers' systems. Architects are trained to solve wicked problems through the integration of the various perspectives expressed by clients, users and other professionals which is part of their training. Engineer training does not take into account this type of problem-solving.

An emerging approach is to immerse students in situated learning contexts that either embed students in industry practice or simulate industry practice in design laboratories. Design laboratories or studios in particular provide a powerful mechanism for capturing the kinds of complex problems faced by industry. In this environment, students learn less by transfer of knowledge from the professor, and more by reflective action and interaction with students or professionals from various disciplines. The following sub-sections provide examples of each of these learning contexts.

\subsection{Learning from practice, a British Columbia experience}

Research students at the University of British Columbia have been learning industry practices by actively engaging with project teams on construction projects. Students observe project coordination meetings and document the process and challenges 
encountered. In certain situations, students support the project team in their collaborative design process. This can take many forms: (1) creating BIM models of specific areas of concern, (2) generating clash reports that identify conflicts between different systems in the different disciplinespecific BIM models, and (3) assisting with the use of different collaboration technology (e.g., SMART boards). These experiences give the students direct knowledge about the way practitioners work and how technology supports their coordination processes and work practices.

An example of this learning was best exemplified on the Center for Interactive Research on Sustainability project, currently under construction at UBC. The CIRS project was an excellent project to study because the building aims to be the most sustainable development in North America and therefore required innovative design of many building systems. In addition, the building design was developed and coordinated using a variety of BIM tools and collaboration technologies. Several students were actively engaged in this project and studied this project from a variety of perspectives: (1) one MASc student studied the coordination process, investigating how time is spent in meetings and the design artifacts used, and identifying the requirements for interactive workspaces [11], (2) another student identified and characterized the bottlenecks encountered in different meeting environments [12], and (3) another student worked with computer science students to characterize the interactions with different design artifacts [13]. This example illustrates the rich learning environments that can be created by working closely with industry practitioners.

\subsection{A multidisciplinary 'Design Lab' experiment}

Two multidisciplinary design courses, jointly offered by the ETS-Montreal and McGill University's School of Architecture, focused on real projects. The first, taught in 2009, focused on a student facility with special requirements for environmental design. The second, offered in 2011, concentrated on the refurbishment of an obsolete industrial landmark.

In the framework of the first course, programmatically, it comprised of administrative, sports and leisure facilities and included a soccer field, a hockey arena, a swimming pool and an underground parking. Such a complex building faced a variety of structural, systems-organization and spatial challenges.
To facilitate collaborations, a specific technological environment was provided for this integrated design course. Each one of the five teams had an independent work-space, equipped with a PC, a projector, a printer, a discussion board (either a vertically standing interactive (smart) board, an interactive tablet, or an ordinary white board) and Internet and local network access. Students brought their own workstations (mainly laptops).

The teams worked over three two-day iterations, with a two-week interval. Information sessions and software capsules were offered complementing students' design and modeling skills in a BIM environment and included Revit Architecture, Ecotect Analysis, Design Builder and D-Profiler, as well as TeamSpot (for co-situated collaboration). At the end of each iteration, the teams presented their work and demonstrated the value of their proposal with regard to sustainability, financial and technical feasibility and its compliance to the program. Feedback was provided by instructors in the related disciplines (architecture, mechanical and construction engineering). Experts from the industry and representatives from the administration and student association of the ETS were invited to the presentations, and also provided feedback, thus ensuring the participation of the client and the end-user.

The results were quite impressive considering the fact that most of the students were unfamiliar with the suggested software and technologies, and had never collaborated with other disciplines. Further research was conducted on how technological environments influence the role of engineers in an integrated team. Methodologically, data was collected through semi-directed interviews and video recordings of all design sessions. Then, inspired by grounded theory and case study, the data was coded and qualitatively analyzed. The participation of four researchers in the interpretation process enabled a triangulation of the results.

In the framework of the second course, the suggested mixed-use program comprised of: a thermal accumulator, recreational and cultural activities, as well as professional and commercial spaces. The setting was similar to the one described for the 2009 course. As for its structure, an information session followed by a site visit was led by the client, Canada Lands Company, and provided a solid background on the site and its challenges. After having familiarized themselves with the urban context, interacted with their team members and agreed on a main idea for their projects, students designed and developed proposals during two intensive two days integrated design charrettes. 
Following each iteration, the four teams presented their proposals to the instructors, the client and professionals and received constructive feedback to advance their work.

While architecture students were familiar with a variety of software (AutoCAD 2010, SketchUp, Photoshop), engineering students were less acquainted with such design tools. Unfortunately, all were novices in using Revit and Ecotect and opted to use what they knew best, rather than venture into learning new software. Also, Google apps was introduced with the aim to facilitate co-situated collaboration.

In this second course, results were satisfying given the time constraints. Nonetheless, design collaborations remained limited due to the fact that students did not use the same software. The teams in which students interacted well were enthusiastic and stated they had learnt a lot. In one case, however, the team members did not get along so well and this resulted in design decisions being mainly taken by the architect who felt frustrated and considered this a limiting experience.

\section{Discussion and conclusions}

Future architects, engineers, and construction managers are entering an increasingly complex, ever-changing and turbulent world. New skills and technological competencies are required to address the upcoming challenges that they will face. They will not only need tools for problem-solving, but knowledge on how and when to use them efficiently. And beyond design tools, they must recognize that the interaction between team members, their investment in the project and the degree of motivation affect the output, the coherence and quality of any proposal. They must also be better prepared to work collaboratively in unfamiliar and uncertain environments.

The US is making significant progress in addressing these challenges in education. A recent survey demonstrated that BIM is being taught in over half of the programs in the US (Becerik et al. 2011). This early experience also demonstrates the challenges of bringing BIM and integrated practice into the curricula, such as a lack of BIM experts to teach the courses and a lack of resources.

Canada in contrast is seriously lagging behind, both from an industry and educational perspective. There are some signs that this is changing, however, as some large governmental bodies are starting to require BIM on their projects. Canadian universities must respond to these changing requirements to prepare future engineers for these new challenges and emerging industry needs.

This paper hopes to start a dialogue across Canadian educational institutions to devise strategies for how best to incorporate these important changes into the teaching of architects, engineers and construction managers. We must adequately train the next generation to be leaders of integrated processes and technologies.

\section{References}

[1] Lawson, B., How Designers Think: The Design Process Demystified. 2006, Oxford: Architectural Press.

[2] Kuhn, T.S., The structure of scientific revolutions. 1996: University of Chicago press.

[3] Becerik-Gerber, B., D.J. Gerber, and K. Ku, The pace of technological innovation in architecture, engineering, and construction education: integrating recent trends into the curricula. 2011, ITcon.

[4] Broshar, M., Strong N., and Friedman D., Report on integrated practice. 2006, American Institute of Architects.

[5] Hatchuel, A., P. Le Masson, and B. Weil, De la gestion des connaissances aux organisations orientées conception. Revue Internationale des Sciences Sociales, 2002: p. 29-42.

[6] Van de Ven, A.H., Engaged Scholarship: Creating Knowledge for Science and Practice. 2007, Oxford: Oxford University Press. 352.

[7] Simon, H.A., The sciences of the artificial. 1996, Cambridge: MIT Press.

[8] Fruchter, R., A/E/C Teamwork: A Collaborative Design and Learning Space. Journal of Computing in Civil Engineering, 1999. 13(4): p. 261-269.

[9] Winch, G.M., Managing Construction Projects. 2002, Oxford, UK: Blackwell Publishing. 458.

[10] Bucciarelli, L., Designing Engineers 1996, New York: MIT Press.

[11] Fard, M.G., et al. Requirements for a mobile interactive workspace to support design development and coordination. in ICCCBE-XI: 11th Int'l Conf. on Computing in Civil and Building Engineering. 2006. Montreal: ICCCBE.

[12] Cavka, H. Characterizing Bottlenecks in Building Design Coordination Meetings. MASc Thesis, University of British Columbia, April 2010.

[13] Tory, M., Staub-French, S., Po, B., and Wu, F., Physical and Digital Artifact-Mediated Coordination in Building Design. Computer Supported Cooperative Work (CSCW) 2008. 17(4): p. 311-351. 